\title{
STUDY ON EXPERT SYSTEM FOR TOWED WATER-SAVING IRRIGATION MECHANIZATION TECHNOLOGY
}

\author{
$\mathrm{Na} \mathrm{Jia}^{1,2}$, Changle Pang ${ }^{1,2, *}$, Zhuomao $\mathrm{E}^{1,2}$ \\ ${ }^{1}$ China Agricultural University, College of Engineering, 17 Tsinghua East Road, Beijing, \\ 100083 China \\ ${ }^{2}$ Research and Extension Center of Towed Water-saving Irrigation Mechanization \\ Technology, 17 Tsinghua East Road, Beijing, 100083, China \\ *Corresponding author,Tel: +86-10-81682099,Email: pangcl@cau.edu.cn
}

\begin{abstract}
Expert system techniques have been rapidly disseminating into every scientific domain, with many applications being reported within the last decade. Expert system is bringing a new perspective. This paper introduces the towed watersaving irrigation mechanization technology firstly. Then, an emphasis is made on development of the expert system for towed water-saving irrigation mechanization technology. The system's architecture, components and function are described.
\end{abstract}

Keywords: artificial intelligence, expert system, water-saving irrigation, towed watersaving irrigation mechanization technology

\section{INTRODUCTION}

Towed water-saving irrigation mechanization technology is created by Chinese scientists firstly. It is based theoretical principle on no-full irrigation theory and regulated deficit irrigation elements, and taken into account the dry region's circumstances adequately in Northern China. Towed watersaving irrigation mechanization is a kind of new technology that utilizes towing machines which are plentiful in counties, such as various wheeled

Jia, N., Pang, C. and E, Z., 2008, in IFIP International Federation for Information Processing, Volume 259; Computer and Computing Technologies in Agriculture, Vol. 2; Daoliang Li; (Boston: Springer), pp. 1323-1327. 
tractors and agricultural vehicles (Kang, S., 1996). Because towed watersaving irrigation mechanization technology is a kind of new technique, the farmers don't know much about it. In addition, a lack of the effective extensive measure induced that the species of water-saving machine which was spread was not much.

Expert system is a kind of artificial intelligence and information system that can be used to inquire and decision-making, it can assist the towed water-saving irrigation mechanization technology to expanse availably (Bruegge, 2000). This paper reports a research effort in developing the expert system for towed water-saving irrigation mechanization technology. One of the strengths of the system is that it can facilitate both query and diagnosis. Feedback collected from the demonstration and evaluation of the system has provided valuable insights into the issues related to the development and implementation of towed water-saving irrigation mechanization technology in China.

\section{SYSTEM ARCHITECTURE}

Based on users' need analysis, an expert system for towed water-saving irrigation mechanization technology was developed. The system was constructed with Visual C\#. Microsoft SQL Server 2000 running on Windows 2000 Advanced Server was used for the back-end databases. The expert system can be reached through Internet, demand was sent from browsers, and the conclusion was made by servers and sent to the browsers (Mehdi Sagheb-Tehrani, 2006). The system can be reached by multi-users simultaneously through Internet. Decision functions can be realized by the system. Users can choose any of them according to their demands and conditions. The system provides guideline and can be used easily.

Fig. 1 shows the architecture for the system (O'Brien, 2004).

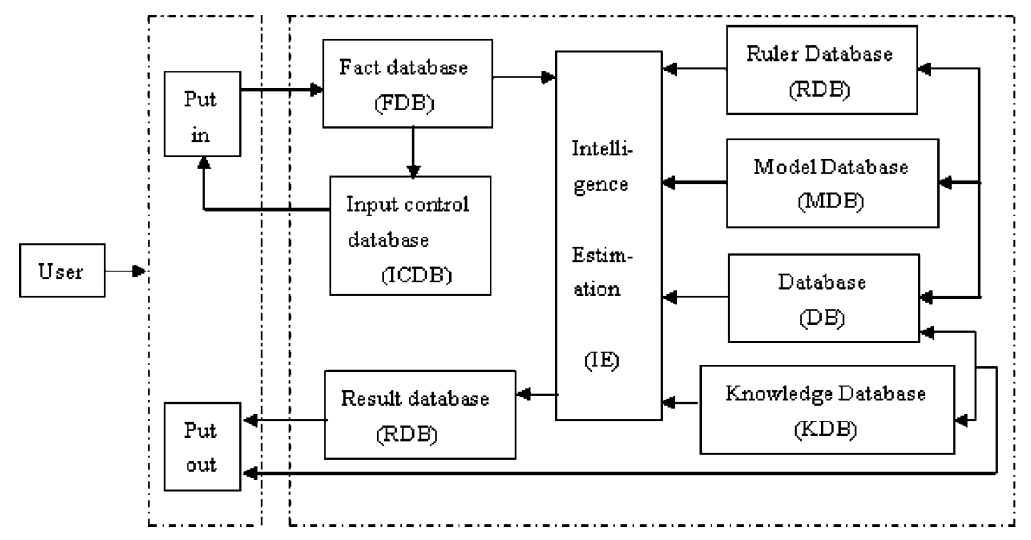

Fig. 1. Structure of the expert system 


\section{SYSTEM COMPONENTS}

To best meet the needs of farmers and experts, four subsystems have been designed and developed in the expert system. The structure of four subsystems can overcome the shortage of each individual system and enhance the overall performance of the expert system. The four subsystems are towed water-saving irrigation machines management subsystem (MMS), water and climate resources management subsystem (WCMS), geography information management subsystem (GMS) and extension system management subsystem (EMS).

The inquiring process is shown in Fig. 2.

More details about each subsystem are discussed as follows:

(1) Towed water-saving irrigation machines management subsystem (MMS):

- To choose the appropriate machine and know about its particular information according to database of machines;

- To ask the users for feedback on the machines.

When a farmer enters into this subsystem, he needs to choose the crop type in first. Then, he needs to choose which period the crop grows to use the irrigation machines. After the farmer submits the demanded information, conclusions such as the best appropriate machine and the machine's detailed information should be given. On the side, farmer can feed back the shortage of machines that he has used.

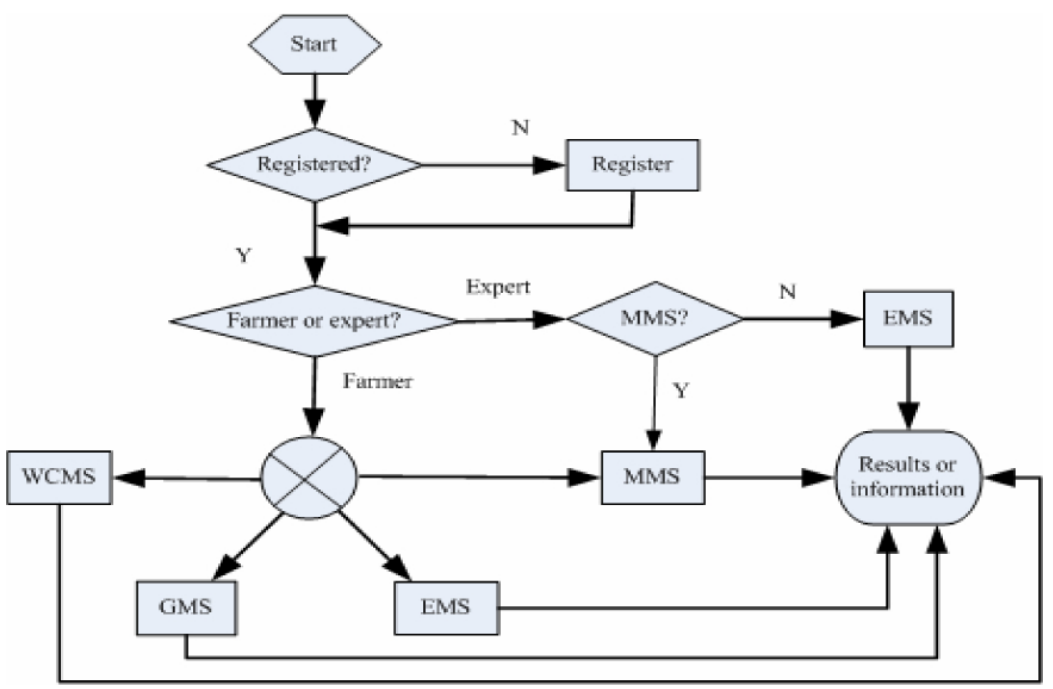

Fig. 2. Working process of the expert system 
(2) Water and climate resources management subsystem (WCMS):

- Distributed conditions of well or water cellar;

- The weather forecast;

- Rainfall and capacity of groundwater supply;

- To decide the amount of irrigative water.

In this subsystem, the farmer needs to input regional name firstly. Then, the system searches correlative water and climate information on Internet. At last, according to mathematics model of database, some prediction such as the amount of irrigation and the plan of water-distributed can be given through calculation.

(3) Geography information management subsystem (GMS):

- To analyze soil condition;

- Distributed condition of dry area;

- To account for the degree of drought and define which dry area the region belongs to.

If farmer enters into this subsystem, he needs to input region he belongs to. Then, a map of this area comes forth. Following the cursor's moving on the map, detailed information about each part of land is provided, such as type of the land, type and name of the soil, gradient of landform, amount of water in the field, etc.

(4) Extension system management subsystem (EMS):

- Extension system;

- The form of extension;

- To choose different service mode according to different region.

Every technology must collocate with appropriate extension system and service mode. In this subsystem, different extension system, the form of extension and service mode can be provided according to the different area that farmers input.

\section{SUMMARY}

This paper reports a research attempt in developing an expert system for towed water-saving irrigation mechanization technology. The system is able to support inquiry on-line. The research demonstrates that the expert system is a good tool to overcome the limitations of the expert in amount and knowledge. The system components and its major function are derived from 
users' suggestions and needs. Further improvement is still being undertaken alongside the collection of more feedback from users. The research demonstrates the structure of four subsystems can overcome the shortage of each individual system and enhance the overall performance of the expert system. The current system can meet different needs of farmers and experts.

\section{ACKNOWLEDGEMENTS}

Funding for this research was provided by the Research and Extension Center of Towed Water-saving Irrigation Technology. We are grateful to $\mathrm{Li}$ Tiejun and Yuan Guodong for their contribution to the data collection and the anonymous referees for their careful reading of the manuscript.

\section{REFERENCES}

Bruegge, B. and A.H. Dutoit, Object-oriented Software Engineering Conquering Complex and Changing Systems, Upper Saddle River, NJ: Prentice Hall, 2000

Kang, S., Cai, H., Liang, Y., 1996. A Discussion of the Basic Theoretical Problem in Crop Water Management of Water-saving Agriculture. J. Hydraulic Eng. (Chinese) 5, 9 \pm 17

Mehdi Sagheb-Tehrani, The Design Process of Expert Systems Development: Some concerns, Expert Systems, vol. 23, issue 2, 2006, pp. 116-125

O’Brien, J.A., Management Information Systems, 6th edn, New York: McGraw-Hill, 2004 